\title{
Genotype Influences In Vivo Dopamine Transporter Availability in Human Striatum
}

\author{
Andreas Heinz, M.D., David Goldman, M.D., Douglas W. Jones, Ph.D., Roberta Palmour, Ph.D., \\ Dan Hommer, M.D., Julia G. Gorey, C.N.M.T., Kan S. Lee, Ph.D., Markku Linnoila, M.D., Ph.D., \\ and Daniel R. Weinberger, M.D.
}

In vivo availability of striatal dopamine transporter (DAT) protein has been reported to be reduced among alcoholics, and allelic variation of the DAT gene (SLC6A3) has been associated with severity of alcohol withdrawal. We examined the VNTR polymorphism of the 3' untranslated region of SLC6A3 and DAT protein availability in 14 abstinent alcoholics and 11 control subjects. Single photon emission computed tomography (SPECT) and plasma levels of the radioligand [I-123] $\beta$-CIT were used to quantify DAT protein availability. Individuals with the 9-repeat/10-repeat genotype had a mean $22 \%$ reduction of DAT protein availability in putamen compared with 10-repeat homozygous individuals $(t=2.14, d f=23, \mathrm{p}<.05)$. Consistent with earlier studies, alcoholism, per se, was not significantly associated with either DAT availability or DAT genotype. These findings suggest that the VNTR polymorphism of the DAT gene effects translation of the DAT protein. This effect may explain a variety of clinical associations that have been reported with this polymorphism. [Neuropsychopharmacology 22:133-139, 2000] Published by Elsevier Science Inc.
KEY WORDS: Dopamine transporter; Gene expression;

SLC6A3; SPECT; $\beta-C I T ;$ Alcoholism

Dysfunction of central dopaminergic neurotransmission has been associated with the development and maintenance of excessive alcohol consumption (Cloninger 1987; Wise 1988; Robinson and Berridge 1993). In animal experiments, ethanol consumption induces dopamine (DA) release in the mesolimbic reward sys-

From the Clinical Brain Disorders Branch (AH, DWJ, JGG, KSL, DRW), DIRP, NIMH, Bethesda, MD; and the Laboratory of Clinical Studies (DG, RP, DH, ML), DICBR, NIAAA, Bethesda, MD.

Address correspondence to: Daniel R. Weinberger, M.D., Chief, Clinical Brain Disorders Branch, NIMH, National Institutes of Health, 10 Center Drive, 4S-235 (MSC 1379), Bethesda, MD 208921379. 1999. tem and may thus reinforce alcohol intake (Mereu et al. 1984; Imperato and Di Chiara 1986). Chronic alcohol consumption has been associated with increased dopamine turnover rate in humans (Heinz et al. 1996a) and with decreased dopamine receptors and transporters in non-human primates (Mash et al. 1996).

Among alcoholics, a reduction in dopamine transporter (DAT) availability has been observed only in late-onset (type I) alcoholics (Tiihonen et al. 1995). The reasons for the reported selective reduction of dopamine transporters in late-onset alcoholics are unclear. They may include genetic and non-genetic factors such as the neurobiological correlates of personality or the effects of chronic alcohol intake (Cloninger 1995; Goldman 1995a,b). Vandenbergh et al. (1992) have identified a polymorphism of the $3^{\prime}$ untranslated region of the DAT gene (SLC6A3) that has been associated with se- 
verity of withdrawal among alcoholics (Sander et al. 1997; Schmidt et al. 1998). The same polymorphism has also been associated with attention deficit hyperactivity disorder (ADHD) in children (Cook et al. 1995) and with the severity of ADHD symptoms (Waldman et al. 1998). Furthermore, Gelernter et al. (1994) observed a significant association of this polymorphism with paranoia induced by cocaine, a potent DAT blocker, and Sabol et al. (1999) recently reported an association of this polymorphism with ease of smoking cessation. Because each of these clinical associations could conceivably be explained by genetically determined variations in synaptic dopamine, we examined the relationship of this polymorphism to variations in the availability of the DAT protein. The variable number of tandem repeat (VNTR) polymorphism in the $3^{\prime}$ region of SLC6A3 was genotyped and the availability of striatal DAT protein was measured in abstinent alcoholics and control subjects. Single photon emission computed tomography (SPECT) with the radioligand [I-123]-2 $\beta$-carbomethoxy$3 \beta$-(4-iodophenyl)tropane ([I-123] $\beta$-CIT) was used to determine the effective binding potential, a quantitative measure of DAT availability (Laruelle et al. 1994).

\section{METHODS}

\section{Subjects}

Fourteen abstinent alcoholics (three females and 11 males) and eleven age-matched control subjects (four females and seven males) participated in this study. All subjects provided written informed consent for this study under protocols approved by the Institutional Review Boards of the Intramural Research Programs of the National Institute on Alcohol Abuse and Alcoholism (NIAAA) or the National Institute of Mental Health (NIMH). All alcohol-dependent patients (mean age: $37 \pm$ 7 years) fulfilled criteria for alcohol dependence according to DSM-IV criteria (American Psychiatric Association 1992).

Exclusion criteria were current drug abuse (a positive urine drug screen) or a past history of drug dependence other than alcoholism, serious head trauma, Korsakoff's syndrome, or the presence of psychiatric (axis I diagnoses; SCID I) (Spitzer et al. 1990a) and neurological diseases unrelated to alcoholism. An extended version of the Michigan Alcohol Screening Tool (Selzer 1971; Fils-Aime et al. 1996) was used to assess prior substance abuse and relatives of the patients were contacted to verify the patients' statements. All patients were abstinent during an inpatient stay in the Intramural Research Program of the NIAAA. Two patients were long-term abstinent alcoholics; in all other patients, SPECT scans were acquired after three to five weeks of supervised abstinence (random breath testing) to avoid confounding effects of alcohol withdrawal on monoam- ine neurotransmission (Rossetti et al. 1992; Heinz et al. 1995, 1996b; Volkow et al. 1996; Laine et al. 1999). Healthy control subjects (mean age: $34 \pm 11$ years) did not meet criteria for any axis I diagnosis or personality disorder (SCID I and SCID II) (Spitzer et al. 1990a,b), had no alcohol-dependent first-degree relatives, and no history of drug or alcohol abuse.

\section{[I-123] $\beta-C I T$ SPECT Procedure}

On the day prior to SPECT scanning, and for three subsequent days, subjects received five drops of Lugol's solution orally to reduce uptake of radioactive iodine into the thyroid. [I-123] $\beta-C I T$ has been shown to bind with high affinity to dopamine transporters (Farde et al. 1994; Seibyl et al. 1994; Tiihonen et al. 1995) in the striatum where radioactive uptake is specifically displaced by ligands binding to dopamine uptake sites (Laruelle et al. 1993). Preparation of [I-123]ß-CIT has been described previously (Baldwin et al. 1993). Each subject received a dose of 222-259 $\mathrm{MBq}(6-7 \mathrm{mCi})$ of [I-123] $\beta$ CIT. The concentration of free [I-123] $\beta$-CIT in blood plasma was assayed by thin layer chromatography of concentrated ultrafiltrates (30 kDa cutoff) (Jones et al. 1997). A 60-minute SPECT scan was acquired 21 hours after injection, when binding at the striatal dopamine transporter is in equilibrium with free [I-123]ß-CIT in blood plasma (Laruelle et al. 1994).

SPECT data were acquired using a CERASPECT (Digital Scintigraphics, Waltham, MA) gamma camera with a high-resolution (7.5 mm FWHM) collimator in 120-projection step-and-shoot mode. The photopeak (145-175 keV) and two windows used for scatter correction (127-145 keV and 175-191 keV) were acquired. Reconstruction by backprojection with a tenth-order Butterworth filter (1 cm cutoff) generated an isotropic volume (1.67 mm voxels) of $64128 \times 128$ transverse slices. The SPECT camera was calibrated prior to each scan session by imaging a 1 liter uniform flood phantom with a radioactivity concentration similar to that observed in brain $(165 \mathrm{nCi} / \mathrm{ml}$ at 21 hours after injection).

To avoid problems associated with multiple statistical tests on this relatively small sample, only two regions of interest (ROIs) were selected for analysis on the basis of the a priori hypothesis that DAT genotype may differentially influence striatal DAT availability in vivo. These ROIs encompassed caudate and putamen in the striatum, areas rich in dopamine transporters with reliably measurable [I-123] $\beta$-CIT binding. Individual regions of interest were drawn for each subject based on MRI scans that were coregistered with the SPECT scans as previously described (Heinz et al. 1998).

Caudate and putamen ROIs were drawn at a midthalamic level; cerebellar ROIs were drawn at the level of the pons. ROIs were measured in five consecutive slices 
forming a volume of interest (VOI) and the average counts per minute per $\mathrm{ml}$ in each VOI was tabulated and corrected for decay. Subtraction of the cerebellum measurement corrected for nonspecific binding. The effective binding potential $\left(\mathrm{BP}^{\prime}=\mathrm{B}_{\text {avail }} / \mathrm{K}_{\mathrm{d}}\right)$ was determined as the ratio of the specific binding to the free [I-123] $\beta$-CIT concentration in plasma, which may be assumed to be equal to the free synaptic concentration of radioligand (Laruelle et al. 1994).

\section{DNA Analyses}

The 3' VNTR polymorphism of SLC6A3, the human DAT gene, was genotyped in 17 abstinent alcoholics (five females and 12 males) and 12 control subjects (four females and eight males). Four subjects (three alcoholics and one control) were included for whom [I-123]ß-CIT SPECT data were unavailable. Genomic DNA was extracted from anticoagulant treated venous blood samples by using a salting-out method (Miller et al. 1988).

DNA amplification by polymerase chain reaction (PCR) of the 40-base pair repeat to detect the 9-repeat and 10-repeat alleles was performed as described elsewhere (Sano et al. 1993). The PCR products were separated by $10 \%$ polyacrylamide gel electrophoresis, silver stained, and fragment sized by comparison with molecular weight standards.

\section{Statistical Analyses}

Statistical analyses were performed using Statistica for Windows, Version 5.1 (StatSoft, Inc., Tulsa, OK; 1998). Due to the relatively small sample sizes and the unequal cell sizes in the analysis of these preliminary data, the impact of DAT genotype and alcoholism on DAT availability in caudate and putamen were assessed with separate Student's t-tests. Genotype frequencies were compared using the chi-squared test. Correlations were assessed with Pearson's linear correlation coefficients.

\section{RESULTS}

Only the two most prevalent 3' VNTR genotypes, the 9-repeat/10-repeat heterozygous (9-10) and 10-repeat/ 10-repeat homozygous (10-10) genotypes, were observed in the DAT genes of this sample of subjects. Although 9-repeat/9-repeat homozygous individuals were not observed, frequencies of the 9-repeat and 10repeat alleles, $23 \%$ and $77 \%$, respectively (Table 1, are similar to those observed by Vandenbergh et al. (1992) $(24 \%$ and $70 \%$, respectively), and did not differ significantly between alcoholics and controls. Moreover, genotype frequencies did not significantly differ from the HardyWeinberg equilibrium either in the overall sample or in alcoholics and controls separately (Table 1). This absence of association between DAT genotype and alcoholism, per se, is consistent with previously published results (Parsian and Zhang 1997; Franke et al. 1999). DAT availability also did not differ significantly between alcoholics and controls in either putamen $(\mathrm{t}=$ $0.80, \mathrm{df}=23, p=.43)$ or caudate $(\mathrm{t}=1.15, \mathrm{df}=23, p=$ .26), consistent with our earlier report on exclusively male subjects (Heinz et al. 1998).

A significant relationship of DAT gene 3' VNTR genotype to DAT availability in putamen was observed $(\mathrm{t}=2.14, \mathrm{df}=23, p<.05)$, with 9-repeat/10-repeat heterozygous individuals exhibiting a mean $22 \%$ lower effective binding potential (mean \pm s.d. $=2226 \pm 635$ ) than 10-repeat homozygous individuals $(2840 \pm 743)$ (Figure 1). The genetic effect in caudate, however, was not significant, though in the same direction $(9-10=$ $2399 \pm 750,10-10=2895 \pm 724 ; \mathrm{t}=1.66, \mathrm{df}=23, p=$ .11). A power analysis reveals that a sample size of 24 subjects of each genotype (48 subjects in all) would be required to have $90 \%$ power to observe a significant effect in caudate based on these data.

To explore the possibility that the observed association between DAT genotype and in vivo DAT availability was the result of extraneous non-genetic factors, several potentially confounding measures were subjected

Table 1. Frequencies of $3^{\prime}$ VNTR Polymorphism of the DAT Gene (SLC6A3) in Alcoholics and Controls

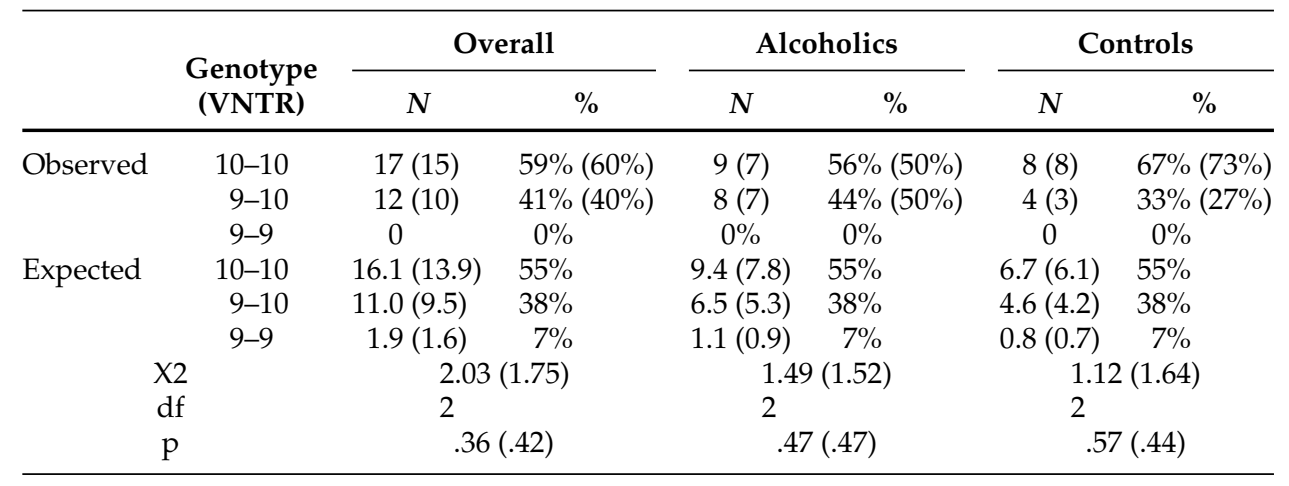

Numbers in parentheses indicate data from subjects for whom [I-123]ß-CIT binding data also was available. 


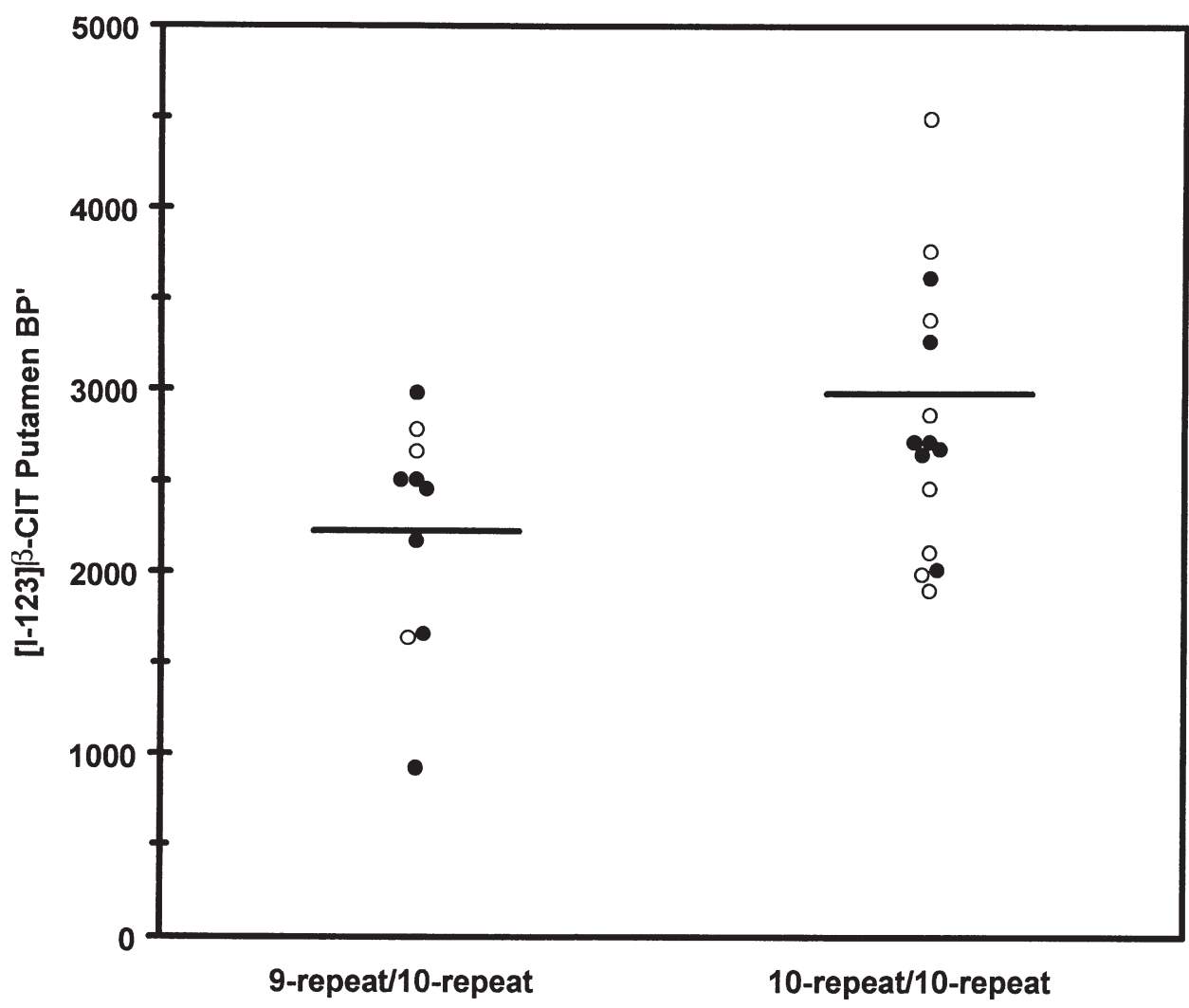

Figure 1. Significant reduction in dopamine transporter (DAT) availability in putamen among 9-repeat/10repeat heterozygous individuals $(N=10)$ compared to 10 -repeat homozygous individuals $(N=15)$ of the $3^{\prime}$ VNTR polymorphism of the DAT gene (SLC6A3) $(\mathrm{t}=2.14$, $\mathrm{df}=23, p<.043)$. Open symbols indicate controls $(N=11)$ and filled symbols indicate abstinent alcoholics $(N=14)$. to post hoc analysis. Mean age did not differ significantly between the two genotype-groups $(9-10=$ $39.0 \pm 10.5 \mathrm{yr}, 10-10=35.1 \pm 10.4 \mathrm{yr} ; \mathrm{t}=0.92, \mathrm{df}=23$, $p=.37)$. No significant correlation between age and DAT availability in putamen was found in either the sample as a whole $(N=25, r=-0.25, p=.22)$ or separately in each genotype-group (9-10: $N=10, r=-0.55$, $p=.10 ; 10-10: N=15, r=0.003, p=.99)$.

All subjects were rated for anhedonia, apathy, and affective flattening with the aid of the Scale for the Assessment of Negative Symptoms (SANS) (Andreasen 1982). None of the SANS measures differed significantly between genotype-groups (all $\mathrm{df}=23$; anhedonia: $\mathrm{t}=0.77, p=0.45$; apathy: $\mathrm{t}=1.62, p=.12$; affective flattening: $t=0.23, p=.82$ ). Neither did any of the SANS ratings correlate significantly with striatal DAT availability for the sample as a whole or for either genotype-group separately (all $|\mathrm{r}|<0.35, p>$.33). Ratings of occupational status and education were assessed using the Hollingshead Four Factor Index of Social Skills (Hollingshead 1973) in 24 subjects (9-10: $N=9,10-10$ : $N=15)$; there were no significant differences between genotype-groups (both $\mathrm{df}=22$, occupation: $\mathrm{t}=0.57$, $p=.58$; education: $\mathrm{t}=0.26, p=.79$ ) and no significant correlations with striatal DAT availability either overall or within-group (all $|\mathrm{r}|<0.32, p>0.21$ ).

Impulsivity ratings from the Impulse Nonconformity Scale (Chapman et al. 1984) were available for 23 subjects (9-10: $N=10,10-10: N=13)$; these too re- vealed no significant differences between genotypegroups $(\mathrm{t}=0.85, \mathrm{df}=21, p=.41)$ and no significant correlations with striatal DAT availability either overall or within-group (all $|\mathrm{r}|<0.27, p>$.45). Likewise, anxiety ratings from the State-Trait Anxiety Inventory (Spielberger et al. 1970) and depression ratings from both the Beck Depression Inventory (Beck et al. 1961) and the Hamilton Depression Rating Scale (Hamilton 1960) were available for a subset of 12 subjects (9-10: $N=8,10-10: N=4$ ) and no significant genotype-group differences or correlations arose. Also, in pre-study screening, clinical interviews and medical examinations revealed no differences that might suggest reduced DAT availability among the 9-repeat/10-repeat heterozygous group relative to the 10-repeat homozygous group. Thus, none of the potentially confounding measures considered accounted for the significant difference in in vivo DAT availability in putamen, which appears to be a consequence of DAT genotype, per se.

\section{DISCUSSION}

This study has found a significant influence of DAT genotype on the in vivo availability of dopamine transporters in human putamen. The 3' VNTR polymorphism of the human dopamine transporter gene, SLC6A3, is located in a 3' untranslated region of the gene (Vandenbergh et al. 1992). While this polymor- 
phism is not associated with an amino acid variation, the $3^{\prime}$ untranslated region can effect mRNA transcription and the corresponding segment of the mRNA molecule can effect mRNA stability as well as translational efficiency. The observation of genotype-dependent differences in the availability of dopamine transporters as measured in vivo by brain imaging implicates an effect of this polymorphism, (or a functional polymorphism to which it is linked), on the molecular mechanisms that account for availability of the DAT protein. The finding also suggests that the mechanism of the $3^{\prime}$ VNTR polymorphism associations to behavior, including clinical aspects of alcohol withdrawal (Sander et al. 1997; Schmidt et al. 1998) and symptoms of ADHD (Cook et al. 1995; Waldman et al. 1998), could be altered abundance of the DAT protein in brain.

While we cannot explain the possibly stronger relationship of this polymorphism to DAT availability in putamen than in caudate, regional and cellular differences in DAT expression might differentially impact the molecular effects of this polymorphism. Another implication of the finding is that nonsystematic variations in the frequency of DAT genotype in clinical populations might be mistaken for true group differences in studies of dopamine transporter availability, especially if small subgroups of patients are assessed.

Although these results are clearly preliminary, in view of the relatively small number of subjects examined, the data may have implications for understanding the clinical associations with the DAT genetic polymorphism that have been reported. Each of the associations represents clinical phenomena that have been imputed to variations in synaptic dopamine. The availability of striatal dopamine transporters seems to regulate extracellular dopamine concentrations in vivo (Caron 1996; Heinz et al. 1999).

Among alcoholics, dopaminergic dysfunction during detoxification has been associated with severity of withdrawal (Heinz et al. 1996b). An increased risk for delirium and seizures during withdrawal has been observed in alcoholics who carry the 9-repeat allele of the DAT gene (Sander et al. 1997; Schmidt et al. 1998). Thus, a reduction in dopamine transporter availability among alcoholics with the 9-10 genotype may be of special relevance during withdrawal, when rapid shifts in presynaptic dopamine release occur (Rossetti et al. 1992; Schulteis and Koob 1994). Under such conditions, decreased abundance of the transporter protein might result in decreased clearance of synaptic dopamine. Similarly, decreased abundance of DAT protein may underlie the association observed by Gelernter et al. (1994) between 9-repeat allele carriers and cocaine-induced paranoia: a less effective clearance of synaptic dopamine may render individuals with this genotype more sensitive to drug-induced dopamine surges. A similar argument may explain recent associations of more subtle aspects of behavior to this polymorphism.
Sabol et al. (1999) found that the 9-repeat allele is associated with both relatively low novelty seeking personality scores and successful smoking cessation. Both characteristics could conceivably reflect a relatively greater baseline "set point" of synaptic dopamine (explained by reduced DAT protein), and thus less "craving" for experiences that increase synaptic dopamine, such as the stress of thrills and the surge of dopamine associated with nicotine use. A diminished availability of DAT protein in the 9-repeat allele carriers may lead to these individuals being less likely to pursue putatively dopamine-stimulating behaviors like novelty seeking and smoking; presumably, under unstimulated conditions synaptic dopamine would be more abundant and persist longer in these people. Given the hypothetical role of dopaminergic dysfunction in alcoholism (Cloninger 1987; Wise 1988; Robinson and Berridge 1993), as well as in other forms of drug abuse and addiction (Koob 1996), further in vivo studies on dopamine transporter availability and genotype seem warranted.

Finally, an influence of genotype on DAT availability in vivo also may explain the relationship of this polymorphism to the severity of attention deficit hyperactivity disorder, as the 10-repeat allele is believed to be the high risk allele in this condition (Cook et al. 1995; Waldman et al. 1998). While the neurobiology of ADHD is obscure, and animal models have generally focused on augmented DA activity (Faraone and Biederman 1998), the most reliable clinical treatments are drugs that block the DAT. This drug effect would conceivably be more apparent in 10-10 homozygous individuals in whom DAT protein appears to be more abundant. In fact, in the study of Waldman et al. (1998), genotype was most strongly associated with hyperactivity-impulsivity symptoms, which tend to be the symptoms most reliably improved with DAT blocking drugs (Zametkin and Ernst 1999). In view of the present results, future brain-imaging studies that measure DAT availability in clinical populations probably should assess DAT genotype as an additional control measure.

\section{ACKNOWLEDGMENTS}

A. Heinz is supported in part by the Deutsche Forschungsgemeinschaft (Az: He 2597/1-1)

\section{REFERENCES}

American Psychiatric Association (1992): Diagnostic and Statistical Manual of Mental Disorders, 4th ed. Washington, DC, American Psychiatric Press

Andreasen NC (1982): Negative symptoms in schizophrenia: definition and reliability. Arch Gen Psychiatry 39:784-788 
Baldwin RM, Zea-Ponce Y, Zoghbi SS, Laruelle M, Al-Tikriti MS, Sybirska EH, Malison RT, Neumeyer JL, Milius RA, Wang S, Stabin M, Smith EO, Charney DS, Hoffer PB, Innis RB (1993): Evaluation of the monoamine uptake site ligand $\left[{ }^{123} \mathrm{I}\right]$ methyl $3 \beta$-(Iodophenyl)-tropane- $2 \beta$-carboxylate $\left(\left[{ }^{123} \mathrm{I}\right] \beta-\mathrm{CIT}\right)$ in non-human primates: Pharmacokinetics, biodistribution and SPECT brain imaging coregistered with MRI. Nucl Med Biol 5:597-606

Beck AT, Ward CH, Mendelson M, Mock J, Erbaugh J (1961): An inventory for measuring depression. Arch Gen Psychiatry 4:561-571

Caron MG (1996): Images in neuroscience. Molecular biology. II. A dopamine transporter mouse knockout. Am J Psychiatry 153:1515

Chapman LJ, Chapman JP, Numbers JF, Edell WS, Carpenter BN, Beckfield D (1984): Impulsive nonconformity as a trait contributing to the prediction of psychoticlike and schizotypal symptoms. J Nerv Mental Dis 172:681-691

Cloninger CR (1987): Neurogenetic adaptive mechanisms in alcoholism. Science 236:410-416

Cloninger CR (1995): The psychobiological regulation of social cooperation. Nature Med 1:623-624

Cook EH Jr, Stein MA, Krasowski MD, Cox NJ, Olkon DM, Kieffer JE, Leventhal BL (1995): Association of attention-deficit disorder and the dopamine transporter gene. Am J Hum Genet 56:993-998

Farde L, Halldin C, Mueller L, Suhara T, Karlsson P, Hall H (1994): PET study of [C-11] $\beta$-CIT binding to monoamine transporters in the monkey and human brain. Synapse 16:93-103

Faraone SV, Biederman J (1998): Neurobiology of attentiondeficit hyperactivity disorder. Biol Psychiatry 44:951958

Fils-Aime ML, Eckhardt MJ, George DT, Brown GL, Mefford I, Linnoila M (1996): Early-onset alcoholics have lower cerebrospinal fluid 5-hydroxyindolacetic acid levels than late-onset alcoholics. Arch Gen Psychiatry 53:211216

Franke P, Schwab SG, Knapp M, Gansicke M, Delmo C, Zill $\mathrm{P}$, Trixler M, Lichtermann D, Hallmayer J, Wildenauer DB, Maier W (1999): DAT1 gene polymorphism in alcoholism: A family-based association study. Biol Psychiatry 45:652-654

Gelernter J, Kranzler HR, Satel SL, Rao PA (1994): Genetic association between dopamine transporter protein alleles and cocaine-induced paranoia. Neuropsychopharmacology 11:195-200

Goldman D (1995a): Identifying alcoholism vulnerability alleles. Alc Clin Exp Res 19:824-831

Goldman D (1995b): Candidate genes in alcoholism. Clin Neurosci 3:174-181

Hamilton M (1960): A rating scale for depression. J Neurol Neurosurg Psychiatry 223:1-8

Heinz A, Lichtenberg-Kraag B, Sällström Baum S, Gräf K, Krüger F, Dettling M, Rommelspacher H (1995): Evidence for prolonged recovery of dopaminergic transmission in alcoholics with poor treatment outcome. J Neural Transm 2:149-158

Heinz A, Dufeu P, Kuhn S, Dettling M, Graef KJ, Kuerten I, Rommelspacher H, Schmidt LG (1996a): Psychopatho- logical and behavioral correlates of dopaminergic sensitivity in alcohol-dependent patients. Arch Gen Psychiatry 53:1123-1128

Heinz A, Schmidt K, Sällström Baum S, Kuhn S, Dufeu P, Schmidt LG, Rommelspacher H (1996b): Influence of dopaminergic transmission on severity of withdrawal syndrome in alcoholism. J Stud Alcohol 57:471-474

Heinz A, Ragan P, Jones DW, Hommer D, Williams W, Knable MB, Gorey JG, Doty L, Geyer C, Lee KS, Coppola R, Weinberger DR, Linnoila M (1998): Reduced serotonin transporters in alcoholism. Am J Psychiatry 155:1023-1028

Heinz A, Saunders RC, Kolachana BS, Bertolino A, Jones DW, Gorey JG, Bachevalier J, Lee KS, Knable MB, Saunders RC, Weinberger DR (1999): Disinhibition of subcortical dopaminergic neurotransmission in rhesus monkeys with neonatal mesial temporal lesions. Synapse 39:71-79

Hollingshead AB (1973): Four Factor Index of Social Skills. New Haven, CT, Yale University

Imperato A, Di Chiara G (1986): Preferential stimulation of dopamine release in the nucleus accumbens of freely moving rats by ethanol. J Pharmacol Exp Ther 239:219228

Jones DW, Heinz A, Gorey JG, Lee KS, Knable MB, Urbina RA, Weinberger DR (1997): A simple, sensitive and efficient method of directly determining plasma concentrations of free [I-123] $\beta$-CIT at extended times by TLC of ultrafiltrates. J Nucl Med 38(Suppl):287P

Koob GF (1996): Drug addiction: The yin and yang of hedonic homeostasis. Neuron 16:893-896

Laine TP, Ahonen A, Torniainen P, Heikkilä J, Pyhtinen J, Räsänen P, Niemelä O, Hillborn M (1999): Dopamine transporters increase in human brain after alcohol withdrawal. Mol Psychiatry 4:189-191

Laruelle M, Baldwin RM, Malison RT, Zea-Ponce Y, Zoghbi SS, Al-Tikriti MS, Sybirska EH, Zimmermann RC, Wisniewski G, Neumeyer JL, Milius RA, Wang S, Smith EO, Roth RH, Charney DS, Hoffer PB, Innis RB (1993): SPECT imaging of dopamine and serotonin transporters with [123-I] $\beta-C I T:$ Pharmacological characterization of brain uptake in non-human primates. Synapse 13: 295-309

Laruelle M, Wallace A, Seibyl JP, Baldwin RM, Zea-Ponce Y, Zoghbi SS, Neumeyer JL, Charney DS, Hoffer PB, Innis RB (1994): Graphical, kinetic, and equilibrium analyses of in vivo [123-I] $\beta$-CIT binding to dopamine transporters in healthy human subjects. J Cerebr Blood Flow Metab 14:982-994

Mash DC, Staley JK, Doepel FM, Yound SN, Ervin FR, Palmour RM (1996): Altered dopamine transporter densities in alcohol-preferring vervet monkeys. NeuroReport 7:457-462

Mereu G, Fadda F, Gessa GL (1984): Ethanol stimulates the firing rate of nigral dopaminergic neurons in unanesthetized rats. Brain Res 292:63-69

Miller SA, Dykes DD, Plesky HF (1988): A simple salting out procedure for extracting DNA from human nucleated cells. Nucleic Acids Res 16:1215

Parsian A, Zhang ZH (1997): Human dopamine transporter gene polymorphism (VNTR) and alcoholism. Am J Med Genet 74:480-482 
Robinson TE, Berridge KC (1993): The neural basis of drug craving: An incentive-sensitization theory of addiction. Brain Res Rev 18:247-291

Rossetti ZL, Melis F, Carboni S, Diana M, Gessa GL (1992): Alcohol withdrawal in rats is associated with a marked fall in extraneural dopamine. Alc Clin Exp Res 16:529-532

Sabol SZ, Nelson ML, Fisher C, Gunzerath L, Brody CL, Hu S, Sirota LA, Marcus SE, Greenberg BD, Lucas FR, IV, Benjamin J, Murphy DL, Hamer DH (1999): A genetic association for cigarette smoking behavior. Health Psychol 18:7-13

Sander T, Harms H, Podschus J, Finckh U, Nickel B, Rolfs A, Rommelspacher H, Schmidt LG (1997): Allelic association of a dopamine transporter gene polymorphism in alcohol dependence with withdrawal seizures or delirium. Biol Psychiatry 41:299-304

Sano A, Kondoh K, Katimoto Y, Kondo I (1993): A 40-nucleotide repeat polymorphism in the human dopamine transporter gene. Hum Genet 91:405-406

Schmidt LG, Harms H, Kuhn S, Rommelspacher H, Sander T (1998): Modification of alcohol withdrawal by the A9 allele of the dopamine transporter gene. Am J Psychiatry 155:474-478

Schulteis G, Koob G (1994): Neuropharmacology: Dark side of drug dependence. Nature 371:108-109

Seibyl JP, Wallace E, Smith EO, Stabin M, Baldwin RM, Zoghbi S, Zea-Ponce Y, Gao Y, Zhang WY, Neumeyer JL, Zubal IG, Charney DS, Hoffer PB, Innis RB (1994): Whole-body biodistribution, radiation absorbed dose and brain SPECT imaging with Iodine-123- $\beta$-CIT in healthy human subjects. J Nucl Med 35:764-770

Selzer ML (1971):The Michigan Alcoholism Screening Test: The quest for a new diagnostic instrument. Am J Psychiatry 127:1653-1658
Spielberger CD, Gorsuch RL, Lushene RD (1970): STAI Manual. Palo Alto, CA, Consulting Psychologists Press

Spitzer R, Williams J, Gibbon M, First M (1990a): Structured Clinical Interview for DSM-III-R-Patient Edition (with Psychotic Screen) (SCID I, version 1.0). Washington, DC, American Psychiatric Press

Spitzer RL, Williams JBW, Gibbon M, First MB (1990b): Structured Clinical Interview for DSM-III-R -Personality Disorders (SCID II, version 1.0). Washington, DC, American Psychiatric Press

Tiihonen J, Kuikka J, Begström K, Hakola P, Karhu J, Ryynänen OP, Föhr J (1995): Altered striatal dopamine re-uptake sites in habitually violent and non-violent alcoholics. Nature Med 1:654-657

Vandenbergh DJ, Persico AM, Hawkins AL, Griffin CA, Li X, Jabs EW, Uhl GR (1992): Human dopamine transporter gene (DAT1) maps to chromosome 5p15.3 and displays a VNTR. Genomics 14:1104-1106

Volkow ND, Wang G, Fowler JS, Logan J, Hitzeman R, Ding YS, Pappas N, Shea C, Piscani K (1996): Decreases in dopamine receptors but not in dopamine transporters in alcoholics. Alc Clin Exp Res 20:1594-1598

Waldman ID, Rowe DC, Abramowitz A, Kozel ST, Mohr JH, Sherman SL, Cleveland HH, Sanders ML, Gard JMC, Stever C (1998): Association and linkage of the dopamine transporter gene and attention-deficit hyperactivity disorder in children: Heterogeneity owing to diagnostic subtype and severity. Am J Hum Genet 63:1767-1776

Wise RA (1988): The neurobiology of craving: Implications for the understanding and treatment of addiction. J Abn Psychol 97:118-132

Zametkin AJ, Ernst M (1999): Problems in the management of attention-deficit-hyperactivity disorder. New Eng J Med 340:40-46 